\title{
Development and Explanation of a Framework for Social Reading: Social Reading Based on Shared Regulation (SRBSR)
}

\author{
Chen Guo $^{1 *}$, Xiangdong Chen ${ }^{2}$ \\ ${ }^{1}$ University at Albany, New York State, US \\ ${ }^{2}$ East China Normal University, Shanghai, China \\ Email: guochen_1989@126.com
}

\begin{abstract}
With the development of technologies for reading and the rise of social reading which considers readers the core in learning and emphasizes sharing and interaction, traditional theoretical reading models are facing challenges. Social reading is a type of interactive reading activity that can activate readers' reading and discussions, promote expressions of multiple ideas, and facilitate collaborative inquiry and knowledge building. While previous researchers proposed theories or frameworks in reading or literacy research, no specific model has been developed especially for social reading and socially shared regulation. Integrating the socially shared regulation theory into social reading and expanding the theoretical perspective of problem-solving on reading can be beneficial for constructing a new social reading model. In this study, we propose a theoretical framework, Social Reading Based on Shared Regulation (SRBSR), which can account for the details and procedures of readers' collaborative learning and shared regulatory behaviors during social reading activities. This framework can help improve the theory of purposeful reading in the new media environment and provide future instructors and researchers an operable model for designing and developing social reading courses.
\end{abstract}

Keywords: social reading, shared regulation, knowledge building, activity theory

\section{Introduction}

Reading requires a combination of many skills and processes in which readers interact with printed words and texts not only for content and pleasure, but also for the growth of information and knowledge (Hussein, 2012; Pourkalhor \& Kohan, 2013). Early studies suggested 'a simple view of reading' in which reading was thought to consist of only two components, decoding and linguistic comprehension (Gough \& Tunmer, 1986; Hoover \& Gough, 1990). This perspective considers the teaching practices of reading as the instruction and cultivation of reading skills and methods. In other words, 'a simple view of reading' highlights the significance of declarative knowledge and procedural knowledge related to reading, which can be acquired in a standardized way that is convenient for analysis, measurement, and management (Chen \& Guo, 2019). However, In the new media age, since the increasing complexity of the readings in contents, culture, and features, along with the emergence and application of new information and communication technologies for literacy teaching and learning, the formats of texts and the ways of reading need to be altered and redefined (Dai, 2015; Leu, et al., 2007). How to better understand reading theoretically and practically from the perspective of learning science and how to effectively improve the teaching practices in reading are critical problems to be resolved.

Social reading is a reader-centered mode of reading and focuses on the facilitation of readers' sharing and interaction, encourages expressions of ideas, and promotes collaborative inquiry. (Chen, 2013; Cordón-García, Alonso-Arévalo, Gómez-Díaz, \& Linder, 2013). As a type of interactive reading activity, readers are required to have a complex process of comprehension, a great variety of reading skills, and a high level of cognitive engagement. Organizations or tools that possess the characteristics of social reading include: offline reading clubs, library reading salons, online reading community, interactive e-books, collaborative annotation systems, reading activities based on social network software, and so on (Chen, 2013; Chanlin, 2013; Kelly, Brian, Gary, \& Eric, 2018; Trott \& Naik, 2012). Different from traditional paper-based reading, the rapid development of social reading has a great impact on readers' consumption of texts (Wu \& Wu, 2017). And social reading pays more attention to social interaction during and after reading, advocates readers' self-generated content, and promotes the circulation and dissemination of information (Swann \& Allington, 2009). In this study, we plan to introduce a new theoretical framework especially for social reading and its theoretical roots. This framework can be employed to explain the details and procedures of readers' collaborative learning and socially shared regulatory behaviors during social reading activities. 


\section{Theoretical perspectives}

\subsection{Knowledge building}

From Vygotsky's (1986) sociocultural view, reading is a complex process of development that can be influenced by many factors, such as topic familiarity, cultural schemata, reader's beliefs and goals, social situations the mediated learning, and the role of active action in learning (Paris \& Hamilton, 2009; Vygotsky, 1986). Rosenblatt (1978) argued that reading is a social activity that entails a transaction between the reader and the text, and that the meaning of texts and discourses are varied from community to community. Bereiter and Scardamalia (1987) introduced two models of composing process: knowledgetelling and knowledge-transforming. The models led the researches on reading and writing to the exploration of how learners build and organize the content they read in their minds and use the knowledge to solve problems. Deeply believed in the knowledge-creating civilization that knowledge is created by communities and realized the significance of collaborative development of shared knowledge, they later put forth the important concept of knowledge building (Scardamalia \& Bereiter, 1993, 2006). Advocates of the knowledge building theory explored how to promote cognitive development in the process of social reading based on the principles of knowledge building (Chen \& Du, 2017; Doto, 2015; Lupo, Berry, Thacker, Sawyer, $\&$ Merritt, 2019). These studies focused on how to facilitate readers and learners to become active knowledge contributors and undertake collective responsibility for the community of practice during social reading activities.

\subsection{Activity theory}

As social reading is considered a format of collaborative learning, it is necessary to bridge the cognitive gaps among students and help them learn strategic control of their actions, thinking, and beliefs in the process of social interactions (Hadwin, Järvelä, \& Miller, 2011, Chen, 2013). Therefore, an important question emerges: what types of reading activities can promote students' social and cognitive agents during purposeful reading? Researchers attempted to answer this question using the framework of cultural-historical activity theory (Barrett-Tatum, 2015; Engeström, 2008; Johnson, 2003; Leont'ev, 1978). Activity theory provides a conceptual framework that views the system of object-oriented collective activity as the basic unit for the analysis of individual practices and development (Arnseth, 2008; Yamazumi, 2017). This theoretical perspective helps analyze how classroom interaction and collaboration in the social reading process can improve readers' reading motivation, facilitate their participation in reading activities, and encourage them to become productive learners (Wu $\& \mathrm{Wu}, 2017)$.

\subsection{Socially shared regulation}

Grounded in early conceptualizations of self-regulated learning (Zimmerman, 2000), regulation of learning can be defined as an intentional, goal-directed metacognitive activity in which learners and groups take strategic control of their actions, thinking, and beliefs in the context of dynamic social interactions (Hadwin, Järvelä, \& Miller, 2011; Iiskala, Vauras, Lehtinen, \& Salonen, 2011; Volet, Summers, \& Thurman, 2009). Hadwin and Oshige (2011) suggested three types of regulation that learners should possess for achieving success: self-regulation, co-regulation, and socially shared regulation. Specifically, socially shared regulation (SSR) refers to the process by which learners or readers regulate their collective activity (Hadwin, Järvelä, \& Miller, 2011). SSR involves interdependent or collectively shared regulatory processes, beliefs, and knowledge (e.g., task perceptions, goals, strategies, monitoring, evaluation, metacognitive decision making) coordinated toward a co-constructed or joint outcome (Miller \& Hadwin, 2015). In computer-supported collaborative learning (CSCL) settings, SSR can facilitate both individual and collaborative knowledge building, mutual negotiation, sustained learning, and information sharing (Zheng, Li, Huang, 2017). Particularly, when SSR occurs in social reading activities, readers or learners are supposed to collaboratively negotiate task goals and standards, strategically select tools and strategies, monitor each other's progress during the reading processes and adapt task perceptions, goals, and engagement to optimize their own engagement in the tasks (Miller \& Hadwin, 2015).

\subsection{Purposeful reading and RESOLV model}

As mentioned, studies in the field of reading and literacy began to break through the traditional hypothesis of the "simple view of reading" (Gough \& Tunmer, 1986; Hoover \& Gough, 1990) at theoretical and empirical levels. The purposeful reading theory and the reading as the process of problem-solving perspective have attracted the attention of researchers (Flynn, 1989; Kim \& Ma, 2016; Rouet, Britt, \& Durik, 2017). A growing number of studies indicated that reading is driven by readers' purposeful decision making (Paris \& Hamilton, 2009). Readers can independently set their reading goals, which usually come from their interaction with the physical and social contexts (Rouet, Britt, \& Durik, 2017). A critical statement claimed that readers' purposes may determine not only their engagement in reading, but their decision to continue or give up reading tasks, regardless of how much they have already read contexts (Britt, Rouet, \& Durik, 2017). 
The RESOLV (REading as problem-SOLVing) framework serves as the building blocks for our newly proposed model. The RESOLV emphasizes the view that reading behavior occurs within a physical and social context that prepares enough resources and conditions for reading (Winne \& Hadwin, 1998). This framework proposed two models that can be established precede reading, namely, the context model and the task model (Rouet, Britt, \& Durik, 2017). The former is a representation of the physical and social context before any reading behaviors (Snow and the RAND Reading Group, 2002), and the latter one is a subjective representation of the goal to be fulfilled and the methods to achieve it (Cerdan, Gilabert, \& Vidal-Abarca, 2011). The underlying assumption of RESOLV is that reading involves a series of complex cognitive activities. Readers make decisions on what to read and how to read not only according to their interpretation of the task requirements, but the representation of contextual cues (Rouet, Britt, \& Durik, 2017).

\section{Framework proposal}

Building upon the above-mentioned theoretical perspectives, we develop a new framework called Social Reading based on Shared Regulation (SRBSR), as can be seen in Figure 1. The basic hypothesis of the SRBSR is reading takes place in specific physical and social settings that can provide readers sufficient resources and conditions. This framework extends the original RESOLV framework (Rouet, Britt, \& Durik, 2017) by including key characteristics of social reading and SSR. SRBSR identifies four dimensions that can influence the social reading processes: demands and sources, supporting conditions, individual and collective characteristics, and other (influential) factors. The demands and sources can be caused by two situations, one is the requirements in the format of specific instruction, such as an instructor asks a student to read a book chapter. The other is the problems that arise from the interactive process of communication and collaboration. The supporting conditions designate the external resources that readers may draw upon and the potential environmental difficulties they may encounter, such as limited reading materials, space and time constraints, and insufficient scaffolding. Individual and collective characteristics include readers' motivation, interests, and values of reading, as well as the social network structure of reading communities. Besides, other factors may impact the generation of the reader context model, such as breaking news or an incident that happens unexpectedly.

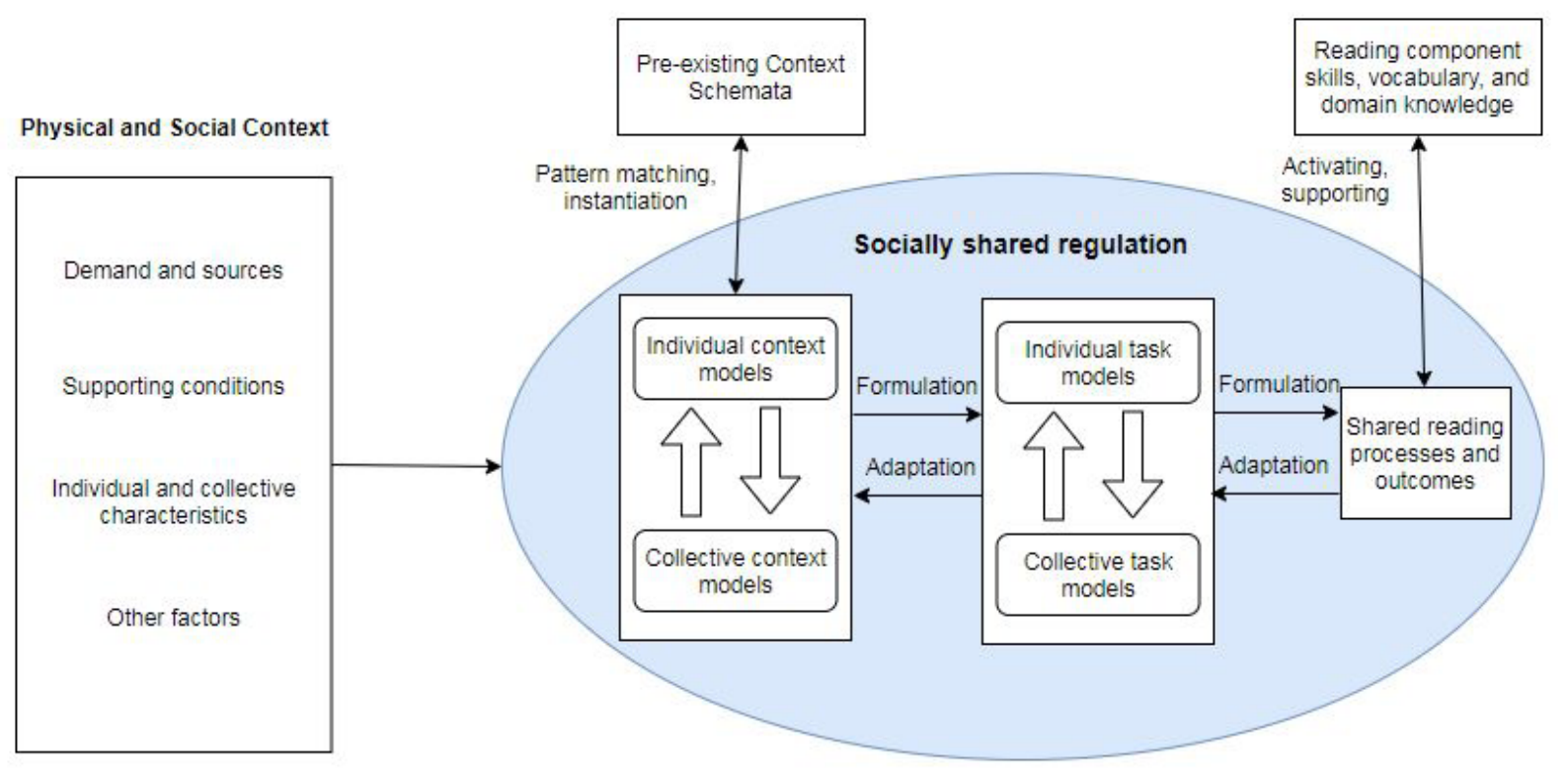

Figure 1. Social reading based on shared regulation (srbsr) framework

SRBSR assumes two shared resources of the individual or group readers that may directly relate to reading: pre-existing context schemata and reading component skills, vocabulary, and domain knowledge. Before participating in social reading activities, readers are supposed to take advantage of their pre-existing cognitive schema for pattern matching or instantiation to construct the context models (Rouet, Britt, \& Durik, 2017). The reading skills, vocabulary, and knowledge serve as the foundation for decoding and comprehend contents in the paper or other formats.

One significant difference between RESOLV and SRBSR is that our proposed framework incorporates the mechanism of SSR, which means when readers are dealing with reading tasks, they would not only involve in the self-regulation, but also use SSR strategies such as shared task comprehension, goal planning, monitoring, controlling, and reflecting on the 
outcomes. Additionally, SRBSR defines three types of constructs related to social reading, namely, individual and shared context models, individual and shared task models, and shared reading processes and outcomes.

\subsection{Individual and shared context models}

The individual and shared context models are subjective representations of the surrounding physical and social context prior to the reading experiences. Individual and shared context models are relatively stable and centered around the request or need for reading. Based on the context models. As mentioned, the elements of the physical and social context in which the readers involve can be divided into four dimensions. Each dimension includes specific information that requires capturing under different reading circumstances. For instance, a reader would formulate two different representations of the reading task when they respond to explicit instructions from others (e.g. family members, teachers, classmates) and to more implicit cues (e.g. reading before doing the homework or completing a mission of a game) (Rouet, Britt, \& Durik, 2017). In addition to readers' representations of the factors in the physical and social context, the context models also include the representations performed by readers with their pre-existing knowledge, reading experiences, and disposition characteristics. Within the context models, reading is not only an individual action but involves a series of collective behaviors based on the process of socially shared regulation. The reading groups can characterize key factors in the physical and social context through negotiating and communicating with other group members, sharing personal concepts and ideas, and learning from others' reading skills and experiences.

\subsection{Individual and shared task models}

Different with the context models, individual and shared task models are dynamic cognitive models that can be updated frequently. The task models include things that readers plan to do and how they are going to do to meet the reading requirements. Individual and shared task models process involve selecting implicit or explicit cues from the context models, resolving the requests, setting and updating plans or goals, and finally detecting and removing barriers and impasses. The reading goals represent the reading requirements of reading tasks which can be either clear or fuzzy. Notably, since the reading requirements may not contain the instructions of procedures for completing reading tasks, readers need to make specific reading plans and choose appropriate strategies according to their abilities and experiences.

\subsection{Shared reading processes and outcomes}

In the process of social reading, readers or learners in a community are supposed to participate in individual and collective reading towards the shared tasks. They normally co-construct the task models through the construction of the context models in advance. The reading processes and outputs are not only affected by the readers' reading goals and plans within the task models, but their pre-existing skills, vocabulary, and knowledge as well. The reading processes are iterative and repetitive, as the outcomes of the previous reading phase can lead to the initiating of the next reading phase. A typical procedure of a social reading activity based on SSR can include (1) co-construct shared perceptions of the reading tasks, (2) negotiate shared reading goals, standards, and plans for accomplishing the tasks, (3) collaboratively draw upon cognitive, social-emotional, behavioral, and motivational strategies, (4) strategically adapt shared task perceptions, goals, and engagement to optimize collaboration in the reading processes (Miller \& Hadwin, 2015; Winne \& Hadwin, 1998), (5) note down individual reflections and share the outputs to others, and (6) evaluate the whole social reading processes and the final outputs.

\subsection{Relationship among the constructs}

The relationships among the context models, the task models, and shared reading processes and outcomes are not linear and sequential. Through feature extraction, pattern matching, and activation of pre-existing schemata, the context models can be built. The task models utilize the content models including the encoded instructions or requests and genre schema to create goals and plans. The reading process is iterative, the outcomes in each reading stage will appear and may be used in the next stage. Since the initial task models are probably incomplete and vague, the outcomes generated in the reading stage may also cause an effect on the readers' understandings of the reading goals and plans, then the previous task models can be eventually adjusted and updated.

\section{Implications and future works}

Current reading and literacy research tend to develop or employ more complicated frameworks. The SRBSR framework emphasizes pre-existing backgrounds and experiences of readers and learners and considers reading comprehension as a multi-level and situational activity. This study elaborates the reading mechanism in the new media environment from the perspective of socially shared regulation and reveals influential factors and dynamic development processes of social 
reading. Our proposed framework can be employed and extended for future research on social or collaborative reading and shared regulatory behaviors in reading activities. Some potential directions are listed as follows:

\subsection{Empirical studies on SRBSR}

Compared to the RESOLV framework (Rouet, Britt, \& Durik, 2017), the SRBSR includes the SSR theory and puts more emphasis on the dimension of the collaborative learning aspect in the social reading processes. Therefore, there is a need to discover more details on the characteristics of social reading and to raise corresponding hypotheses for empirical research. And how to achieve shared task understanding at both individual and collective levels, and how to combine shared and self-regulation of learning during social reading activities to generate productive outcomes should be research questions worthy of investigation. Additionally, in the process of the formation of the context models and the task models, the SSR of "problem-solving" and that of reading task understanding should be active and dynamic. Identifying the factors which can impact the process of SSR among readers requires more research as well.

\subsection{Scaffolds and tools for social reading}

The application of SRBSR framework in the reading class practices requires a certain degree of interventions and scaffolds to promote the construction of the context models and the task models. Characteristics and principles of SSR and social reading may be realized by utilizing scaffolds and customized tools in the teaching practices of reading. Since social reading is usually embedded in many types of collaborative activities and the objectives of reading tasks are relatively complicated and diverse, a single scaffold may not provide due reinforcements for such learning or reading activities. The infusion of various types of scaffolds into reading instruction can help create a comprehensive learning environment, which is conducive to the readers' community of inquiry (Tabak, 2004). Besides, to better support the use of scaffolds, the development and application of customized tools or technologies for social reading, such as the Social Reading Platform (Chen \& Guo, 2019), needs more empirical studies.

\subsection{Reading classroom practices based on SRBSR}

The effect of SRBSR on practical reading instruction can be mainly reflected in two aspects. First, it pays more attention to the implicit phenomenon in classroom practices, such as how students decide to read the reading content, how students develop reading plans and strategies, and when students suspend their reading behaviors. These metacognitive level questions are crucial to students' reading and learning. Besides, as social reading is a format of collaborative learning activity, classroom practices can be carried out mainly from two aspects: First, based on the SRBSR framework, instructors can design different reading strategies and corresponding reading activities for specific subject matters. These reading activities should conform to the characteristics of individual readers and reading groups and aim at encouraging students' participation in social reading activities and collective knowledge construction. Second, the research scope of the practical application of SRBSR should be expanded. Such as the investigations on possible application modes of social reading in classroom instruction, extra-curricular reading programs, and other knowledge exchanging activities.

\section{References}

[1] Arnseth, H. C. Activity theory and situated learning theory: contrasting views of educational practice. Pedagogy, Culture \& Society. 2008; 16(3): 289-302.

[2] Barrett-Tatum, J. Examining English language arts common core state standards instruction through cultural historical activity theory. Education Policy Analysis Archives. 2015; 23(63): 1-33.

[3] Bereiter, C., Scardamalia, M. The psychology of written composition. Hillsdale, NJ: Lawrence Erlbaum; 1987.

[4] Britt, M. A., Rouet, J.-F., Durik, A. M. Literacy beyond text comprehension: A theory of purposeful reading. New York, NY: Routledge; 2017.

[5] Cerdan, R., Gilabert, R., Vidal-Abarca, E. Selecting information to answer questions: Strategic individual differences when searching texts. Learning and Individual Differences. 2011; 21: 201-205.

[6] Chanlin, L. J. Reading strategy and the need of e-book features. The Electronic Library. 2013; 31(3): 329-344.

[7] Chen, X. Social reading in the new media environment. China Educational Technology. 2013; 6: 21-25.

[8] Chen, X. Du, J. The case study of social annotation teaching based on knowledge building. Modern Distance Education Research. 2017; 4: 78-87.

[9] Chen, X., Guo, C. (2019) The Development and Application of a Social Reading Platform and the Double-level Scaffolding. In: Lund, K., Niccolai, G. P., Lavoué, E., Hmelo-Silver, C., Gweon, G., Baker, M. (Eds.). A Wide Lens: Combining Embodied, Enactive, Extended, and Embedded Learning in Collaborative Settings. Paper presented at the 13th 
International Conference on Computer Supported Collaborative Learning, Lyon, France: International Society of the Learning Sciences.

[10] Cordón-García, J. A., Alonso-Arévalo, J., Gómez-Díaz, R., Linder, D. Social reading: platforms, applications, clouds and tags. Oxford, England: Chandos; 2013.

[11] Dai, S. On the cultivation of new literacies in modern society. Technology Enhanced Foreign Language Education. 2015; 49(5): 645-653.

[12] Doto, J. Supporting Knowledge Building with Informational Texts During Elementary Reading Instruction: A Design based Study. New Brunswic: Rutgers University; 2015.

[13] Engeström, Y. From teams to knots: Activity-theoretical studies of collaboration and learning at work. Cambridge, England: Cambridge University Press; 2008.

[14] Flynn, L. L. Developing critical reading skills through cooperative problem solving. The Reading Teacher. 1989; 42(9): 664-668.

[15] Gough, P. B., Tunmer, W. E. Decoding, reading, and reading disability. Remedial \& Special Education. 1986; 7(1): 6-10.

[16] Hadwin, A. L., Järvelä, S., Miller, M. Self-regulated, co-regulated, and socially shared regulation of learning. In: B. J. Zimmerman, D. H. Schunk (Eds.). Handbook of self-regulation of learning and performance. New York, NY: Routledge; 2011.

[17] Hadwin, A. F., Oshige, M. Self-regulation, coregulation, and socially shared regulation: Exploring perspectives of social in self-regulated learning theory. Teachers College Record. 2011; 113: 240-264.

[18] Hoover, W. A., Gough, P. B. The simple view of reading. Reading \& Writing. 1990; 2(2): 127-160.

[19] Hussein, A. S. Analysis of the real situation of teaching reading comprehension to first year students at the department of English language and literature at Al-Zaytoonah Private University of Jordan. Asian Social Science. 2012; 8(4): 237251.

[20] Iiskala, T., Vauras, M., Lehtinen, E., Salonen, P. Socially shared metacognition of dyads of pupils in collaborative mathematical problem-solving processes. Learning and Instruction. 2011; 21(3): 379-393.

[21] Johnson, D. Activity theory, mediated action and literacy: Assessing how children make meaning in multiple modes. Assessment in Education: Principles, Policy \& Practice. 2003; 10(1): 103-129.

[22] Kelly, M., Brian, L., Gary, K., Eric, M. Use of a social annotation platform for pre-class reading assignments in a flipped introductory physics class. Frontiers in Education. 2018; 3(8): 1-12.

[23] Kim, Y., Ma, J. H. The role of purposeful reading in L2 Learners' reading comprehension, task motivation, and perceived difficulty. Studies in English Education. 2016; 21(1): 73-95.

[24] Leont'ev, A. N. Activity, consciousness, and personality. Englewood Cliffs, NJ: Prentice Hall; 1978.

[25] Leu, D.J., Zawilinski, L., Castek, J., Banerjee, M., Housand, B., Liu, Y. What is new about the new literacies of online reading comprehension? In: L. Rush, J. Eakle, A. Berger (Eds.). Secondary school literacy: What research reveals for classroom practices. Urbana, IL: National Council of Teachers of English; 2007.

[26] Lupo, S.M., Berry, A., Thacker, E., Sawyer, A., Merritt, J. Rethinking text sets to support knowledge building and interdisciplinary learning. The Reading Teacher. 2019; 73(4): 513-524.

[27] Miller, M., Hadwin, A. Scripting and awareness tools for regulating collaborative learning: Changing the landscape of support in CSCL. Computers in Human Behavior. 2015; 52: 573-588.

[28] Paris, S. G., Hamilton, E. E. The Development of Children's Reading Comprehension. In: Israel, S. Duffy, G. (Eds). Handbook of Research on Reading Comprehension. New York, NY: Routledge; 2009.

[29] Pourkalhor, O., Kohan, N. Teaching reading comprehension through short stories in advance classes. Asian Journal of Social Sciences \& Humanities. 2013; 2(2): 52-60.

[30] Rosenblatt, L. M. The reader, the text, the poem: The transactional theory of the literary work. Carbondale: Southern Illinois University Press; 1978.

[31] Rouet, J. F., Britt, M. A. Relevance processes in multiple document comprehension. In: M. T. McCrudden, J. P. Magliano, G. Schraw (Eds.). Text relevance and learning from text. Greenwich, CT: Information Age; 2011.

[32] Rouet, J. F., Britt, M. A., Durik, A. M. RESOLV: Readers' representation of reading contexts and tasks. Educational Psychologist. 2017; 52(3): 200-215.

[33] Scardamalia M., Bereiter C. Computer support for knowledge-building communities. Journal of the Learning Sciences. 1993; 3(3): 265-283.

[34] Scardamalia, M., Bereiter, C. Knowledge Building: Theory, pedagogy, and technology. In R. K. Sawyer (Ed.). Cambridge handbook of the learning sciences. Cambridge: Cambridge University Press; 2006.

[35] Snow, C. E., the RAND Reading Group. Reading for understanding. Toward a R\&D program for reading comprehension. Santa Monica, CA: RAND; 2002.

[36] Swann, J., Allington, D. Reading groups and the language of literary texts: a case study in social reading. Language \& Literature. 2009; 18(3): 247-264. 
[37] Tabak, I. Synergy: a complement to emerging patterns of distributed scaffolding. Journal of the Learning Sciences. 2004; 13(3): 305-335.

[38] Trott, B., Naik, Y. Finding good reads on goodreads. Reference \& User Services Quarterly. 2012; 51(4): 319-323.

[39] Vlieghe, J., Vandermeersche, G., Soetaert, R. Social media in literacy education: Exploring social reading with pre-service teachers. New Media \& Society. 2016; 18(5): 800-816.

[40] Volet, S., Summers, M., Thurman, J. High-level co-regulation in collaborative learning: How does it emerge and how is it sustained? Learning and Instruction. 2009; 19(2): 128-143.

[41] Vygotsky, L. S. Thought and language. Cambridge. MA: The MIT Press; 1986.

[42] Winne, P. H., Hadwin, A. F. Studying as self-regulated engagement in learning. In D. Hacker, J. Dunlosky, A. Graesser (Eds.). Metacognition in educational theory and practice. Hillsdale, NJ: Lawrence Erlbaum; 1998.

[43] Wu, L., Wu, Y. Adolescents' social reading: motivation, behaviour, and their relationship. The Electronic Library. 2017; 35(2): 246-262.

[44] Yamazumi, K. Engaging Children in Reading Activity Through Collaboration in a Japanese Elementary School: An Activity-Theoretical Case Study. In: Ng, C., Bartlett, B. (eds). Improving Reading and Reading Engagement in the 21st Century. Singapore: Springer; 2017.

[45] Zhang, J., Sun, Y. Reading for idea advancement in a grade 4 knowledge building community. Instructional Science. 2011; 39(4): 429-452.

[46] Zheng, L., Li, X., Huang, R. The effect of socially shared regulation approach on learning performance in computer-supported collaborative learning. Journal of Educational Technology \& Society. 2017; 20(4): 35-46.

[47] Zimmerman, B. J. Attaining self-regulation: A social cognitive perspective. In: M. Boekaerts, P. R. Pintrich, M. Zeidner (Eds.). Handbook of self-regulation. San Diego, CA: Academic Press; 2000. 